\title{
Racial differences in the results of glaucoma filtration surgery: are racial differences in the conjunctival cell profile important?
}

\author{
David Broadway, Ian Grierson, Roger Hitchings
}

\begin{abstract}
Conjunctival biopsies were obtained at the time of filtration surgery from 90 patients with glaucoma; 45 of these patients were black and 45 white. Forty nine of the patients ( 25 black, 24 white) had undergone a primary trabeculectomy. Comparisons between black and white patients were made with respect to the results of surgery and differences in conjunctival cell profile. In agreement with many authors, trabeculectomy was found to be less successful in black patients (67\% compared with $80 \%)$, although this finding was not statistically significant by survival analysis. In addition, conjunctiva from black patients was found to contain a greater number of macrophages and a smaller number of both mast cells and goblet cells in comparison with white patients. There was a tendency for conjunctiva from black patients to contain more fibroblasts. Conjunctiva obtained from the patients whose filtration surgery subsequently failed was found to contain more fibroblasts, macrophages, and basal epithelial pale cells. A greater number of conjunctival macrophages and possibly fibroblasts in black patients may partially explain the tendency for a lower success rate of filtration surgery in this group of patients.

(Brf Ophthalmol 1994; 78: 466-475)
\end{abstract}

Trabeculectomy can be a highly successful surgical procedure for the control of intraocular pressure (IOP). A success rate of $98 \%$ has been reported recently in a group of patients with primary open angle glaucoma (POAG) who underwent primary trabeculectomy. ${ }^{1}$ Filtration surgery in certain groups of patients, however, is associated with a significantly lower success rate and known risk factors for filtration failure include age, ${ }^{2}$ previous ocular surgery, ${ }^{3-5}$ secondary glaucoma, ${ }^{6-8}$ and previous therapy with topical antiglaucomatous medications. ${ }^{9-12}$ Moreover, despite the lack of good evidence, black race is generally accepted as a risk factor for failure of filtration surgery. ${ }^{13-15}$

In most patients who undergo successful filtraMoorfields Eye Hospital London D Broadway R Hitchings

Department of Clinical Science, Institute of Ophthalmology, London I Grierson

Correspondence to: David Broadway, Moorfields Eye Hospital, City Road, London ECIV 2PD.

Accepted for publication 26 January 1994 clinical practice such failure tends to occur early (within the first few postoperative months). Early onset failure is associated with a hypercellular response within the bleb, characterised by inflammation and an increase in the number of active fibroblasts. ${ }^{17}$ Therefore the preoperative state of the conjunctiva is of potential importance with respect to the outcome of subsequent filtration surgery.

The aim of this study was to compare the cellular content of the conjunctiva from black and white patients with glaucoma. Furthermore, the study was performed to determine whether any differences in the resident cell population of the conjunctiva and potential cellular mechanisms within the conjunctiva, could explain the relatively poor results of filtration surgery in black patients

\section{Patients and methods}

Conjunctival biopsy specimens were obtained at the time of filtration surgery from 90 patients with glaucoma; 45 black and 45 white. Sixty eight British patients with glaucoma were attending Moorfields Eye Hospital, London, and 22 African patients with glaucoma were from the Eye Hospital, Lunsar, Sierra Leone. Forty five of the British patients were whites and the remaining 23 were black patients of AfroCaribbean origin.

\section{PRIMARY TRABECULECTOMY PATIENTS}

Twenty four of the white, three of the British black patients, and all 22 of the African patients underwent a primary trabeculectomy, within 6 weeks following diagnosis of POAG, or in two cases, pseudoexfoliation glaucoma (PXF). None of these patients had a history of previous ocular surgery, laser therapy, significant ophthalmic (non-glaucomatous) or systemic disease. For the African patients, onchocerciasis was excluded by skin snip analysis and the absence of microfilaria within the anterior chamber at slit-lamp biomicroscopic examination, following 2 minutes of head down posturing in a darkened room.

PATIENTS MATCHED ON NON-RACIAL FACTORS Forty one additional patients had undergone various types of previous therapy. Together with the primary trabeculectomy patients, each individual was matched on the basis of previous therapy and other non-racial factors. Thus, 45 black patients were matched into pairs with 45 white patients. In order of importance, matching was based on glaucoma diagnosis, previous ocular surgery, age, and previous therapy with topical antiglaucoma medications. The matching was performed in a masked fashion from a 
database of 250 glaucoma patients from whom conjunctival biopsies had been obtained.

Full diagnosis matching was achieved, although in order to do this diagnoses of pigment dispersion syndrome (PDS) and PXF were considered comparable to POAG. Forty black patients with POAG were matched with white patients, 35 of whom had POAG, three PXF, and two PDS. Three black patients with uveitic glaucoma, one with chronic primary angle closure, and one with traumatic glaucoma were matched with white patients with the same conditions. Four black patients had undergone previous trabeculectomy. Three of these were matched with white patients who had undergone trabeculectomy and one with a white patient who had undergone a cataract extraction involving a conjunctival incision. One black patient had undergone a peripheral iridectomy and was matched with a patient who had not undergone previous ocular surgery, but had undergone laser trabeculoplasty. The matching was considered justifiable because the iridectomy had been performed via a corneal incision, leaving the conjunctiva undisturbed. Matching on the basis of previous topical therapy took both type of medication and duration of treatment into account.

\section{STUDY A: A COMPARISON BETWEEN THE}

CONJUNCTIVAL CELL PROFILE OF BLACK AND WHITE PRIMARY TRABECULECTOMY PATIENTS

Comparisons were made between the conjunctiva of the 24 white and 25 black primary trabeculectomy patients (see Table 1). The study was performed to compare 'unadulterated' conjunctiva from the two racial groups - that is, conjunctiva unexposed to topical medications (or $<6$ weeks) or surgery. Unfortunately, follow up of the African patients was not available and therefore in the present study it was not possible to compare the effectiveness of filtration surgery with conjunctival status.

\section{STUDY B: A COMPARISON BETWEEN THE}

CONJUNCTIVAL CELL PROFILE OF BLACK AND WHITE PATIENTS MATCHED FOR NON-RACIAL RISK FACTORS

In order to relate any conjunctival differences

Table 1 Black and white primary trabeculectomy patient data

\begin{tabular}{|c|c|c|}
\hline & $\begin{array}{l}\text { White } \\
(n=24)\end{array}$ & $\begin{array}{l}\text { Black } \\
(n=25)\end{array}$ \\
\hline $\begin{array}{l}\text { Mean age (SEM) [range] - years } \\
\text { Sex. }\end{array}$ & $\begin{array}{r}62 \cdot 8(1 \cdot 8) \\
{[46-80]}\end{array}$ & $\begin{array}{r}56 \cdot 8(2 \cdot 4) \\
{[36-76]}\end{array}$ \\
\hline $\begin{array}{l}\text { Sex: } \\
\quad \text { Male } \\
\text { Female }\end{array}$ & $\begin{array}{r}17 \\
7\end{array}$ & $\begin{array}{r}18 \\
7\end{array}$ \\
\hline $\begin{array}{l}\text { Eye: } \\
\text { Left } \\
\text { Right }\end{array}$ & $\begin{array}{l}13 \\
11\end{array}$ & $\begin{array}{l}12 \\
13\end{array}$ \\
\hline $\begin{array}{l}\text { Diagnosis: } \\
\text { POAG } \\
\text { PXF } \\
\text { Previous surgery } \\
\text { Previous laser } \\
\text { Mean duration of topical therapy } \\
\text { (SEM) - months }\end{array}$ & $\begin{array}{l}22 \\
2 \\
0 \\
0 \\
0.9(0.08)\end{array}$ & $\begin{array}{l}25 \\
\overline{0} \\
0 \\
0 \cdot 1(0 \cdot 04)\end{array}$ \\
\hline
\end{tabular}

POAG $=$ Primary open angle glaucoma; $P X F=$ Pseudoexfoliation syndrome.
Table 2 Data for black and white patients matched for nonracial factors

\begin{tabular}{|c|c|c|}
\hline & $\begin{array}{l}\text { White } \\
(n=45)\end{array}$ & $\begin{array}{l}\text { Black } \\
(n=45)\end{array}$ \\
\hline Mean age (SEM) [range] - years & $\begin{array}{r}55 \cdot 2(2 \cdot 0) \\
{[23-76]}\end{array}$ & $\begin{array}{r}52 \cdot 8(2 \cdot 4) \\
{[13-85]}\end{array}$ \\
\hline $\begin{array}{l}\text { Sex: } \\
\quad \text { Male } \\
\text { Female }\end{array}$ & $\begin{array}{l}30 \\
15\end{array}$ & $\begin{array}{l}29 \\
16\end{array}$ \\
\hline Eye: & & \\
\hline $\begin{array}{l}\text { Left } \\
\text { Right }\end{array}$ & $\begin{array}{l}23 \\
22\end{array}$ & $\begin{array}{l}20 \\
25\end{array}$ \\
\hline Diagnosis: & & \\
\hline $\begin{array}{l}\text { POAG } \\
\text { PXF }\end{array}$ & $\begin{array}{r}35 \\
3\end{array}$ & $\begin{array}{r}40 \\
-\end{array}$ \\
\hline PDS & 2 & - \\
\hline PACG & 1 & $\frac{1}{3}$ \\
\hline $\begin{array}{l}\text { Uveitic } \\
\text { Traumatic }\end{array}$ & 1 & $\begin{array}{l}3 \\
1\end{array}$ \\
\hline Previous surgery: & & \\
\hline $\begin{array}{l}\text { Trabeculectomy } \\
\text { ICCE }\end{array}$ & $\begin{array}{l}3 \\
1\end{array}$ & 4 \\
\hline $\begin{array}{l}\text { PI } \\
\text { Previous laser therapy: }\end{array}$ & - & 1 \\
\hline $\begin{array}{l}\text { Previous laser therapy: } \\
\text { LI } \\
\text { LTP }\end{array}$ & $\begin{array}{l}1 \\
2\end{array}$ & $\begin{array}{l}1 \\
5\end{array}$ \\
\hline $\begin{array}{l}\text { Mean duration of topical therapy } \\
\text { (SEM) - months }\end{array}$ & $21 \cdot 03(5 \cdot 8)$ & $25 \cdot 5(8 \cdot 3)$ \\
\hline
\end{tabular}

POAG = Primary open angle glaucoma; $\mathrm{PXF}=$ pseudoexfoliation syndrome; $P D S=$ pigment dispersion syndrome; $P A C G=$ primary angle closure glaucoma; $\mathrm{PI}=$ peripheral iridectomy; $\mathrm{LI}=$ laser iridotomy; LTP=laser trabeculoplasty ICCE = intracapsular cataract extraction.

with the results of filtration surgery and to study a greater number of patients, the study was extended to include 41 additional individuals making the total of 90 patients.

Comparisons were made between the conjunctivae of these 45 white and 45 black patients. Study B had the advantage over study A of a greater number of patients. However, study B was complicated by the fact that patients from both groups had been treated with topical medications. Since there may be racial variability in effect of previous therapy on the cellular status of the conjunctiva, study $B$ was unable to determine simple racial conjunctival differences. Since both racial factors may be important the study was considered to be of value.

As a group, the black patients were of similar mean age to the white patients, with a mean difference of only 6.2 years between pairs (see Table 2). The difference in age between matched patients was $<10$ years in the majority of pairs (38) and only $>20$ years in two cases ( 22 years in one case and 23 in another).

The majority of patients (38) were matched with those who had used the same type or combination of topical medications. In the remaining seven cases, therapy had differed by only one type of medication. Duration of therapy was matched as closely as possible and as a group the duration for black patients (25.5 (SEM 8.3) months; range 0-271 months) was similar to that for the white patients $(21 \cdot 03(5 \cdot 8)$ months; range 0-210 months). In most cases (31) the difference in duration of therapy between matched pairs was $<1$ year.

One black patient had undergone a previous laser iridotomy and was matched with a white patient who had also undergone such a procedure. Five black patients had undergone previous laser trabeculoplasty. Two of these were matched with two similar white patients. In the case of two other pairs, all four patients had undergone additional ocular surgery and the 
influence of the trabeculoplasty was considered relatively insignificant. The remaining case was matched with a patient who had not undergone any laser or surgical therapy but was well matched with respect to the other risk factors. As groups, the patients were comparable for sex, although 13 pairs were unmatched.

STUDY C: THE RESULTS OF GLAUCOMA FILTRATION SURGERY

Follow up was available for all 68 of the British patients and a comparison of the results of filtration surgery between the 45 white and 23 black patients was made possible. Of the patients, for whom follow up was available, 40 white and 15 black patients had undergone their first trabeculectomy. Racial differences in the results of these 55 trabeculectomies were determined.

STUDY D: THE RELATION BETWEEN CONJUNCTIVAL CELL COUNTS AND THE OUTCOME OF

TRABECULECTOMY

Comparisons were made between the preoperative conjunctival cell profiles of those patients whose trabeculectomies were successful with those whose trabeculectomies failed. The study was performed in order to determine whether the cellular status of the preoperative conjunctiva was important in terms of surgical success.

\section{Methods}

\section{CONJUNCTIVAL BIOPSY ASSESSMENT}

Specimens of superior bulbar conjunctiva were obtained with minimal trauma from the nasal or temporal edge of the conjunctival flap at the time of glaucoma filtration surgery. Specimen size varied from about $2 \cdot 5-5 \mathrm{~mm}^{2}$, smaller biopsies being taken when it was felt that larger specimens would compromise the outcome of surgery.

The biopsies were immediately fixed in $2.5 \%$ phosphate buffered glutaraldehyde. After a minimum of 24 hours they were post fixed in 1\% buffered osmium tetroxide, dehydrated through graded alcohols, and embedded in epoxy resin (Araldite, Agar Scientific Ltd, Stanstead). Semithin $0.5 \mu \mathrm{m}$ thick sections were cut using an ultramicrotome (Reichert-Jung Ultracut E, Leica UK Ltd, Milton Keynes) and stained with toluidine blue.

Light microscopic analysis of the specimens was performed using the $\times 100 / 1 \cdot 25$, oil immersion objective of a standard light microscope (Vickers Instruments, Dartford) and $\times 10$ eyepieces fitted with an indexed square grating graticule (Agar Scientific Ltd, Stanstead).

For each specimen the number of goblet cells, pale basal cells, lymphocytes, macrophages, and intraepithelial cysts were counted in the epithelial layer and the number of fibroblasts, macrophages, lymphocytes, plasma cells, mast cells, and granulocytes were counted in the conjunctival substantia propria.

Cell counting and identification were established using rigid criteria. Cells were only counted when both nuclear and cytoplasmic morphology made clear identification of cell type possible. Within the epithelium, basal pale cells were counted. Pale cells include both melanocytes and Langerhans cells, which cannot be distinguished by routine staining and light microscopy. ${ }^{18}$ All intraepithelial cysts were counted, most being hyaline body cysts. ${ }^{19}$ All counts were made in a masked fashion by one of the investigators and 10 specimens were counted twice enabling an intraobserver error to be determined using a simple formula of variance. The counts were not made using the same areas of the same sections and the counting error thus included an element of sampling error. For all cell types the errors were less than $10 \%$ and for fibroblasts less then $5 \%$. Ten specimen counts were made by two investigators permitting an interobserver error to be determined. The counts were made independently but using exactly the same areas of tissue so as to measure the accuracy of the cellular identification criteria. For all cell types the errors were less than $7 \%$ and for fibroblasts less than $3 \%$.

Cell counts were based on $2 \mathrm{~mm}$ lengths of epithelium and $0.2 \mathrm{~mm}^{2}$ of subepithelial tissue. With all the specimens a count was made in the epithelium and superficial substantia propria (the most superficial $0.1 \mathrm{~mm}$ ). When possible a further count was made in deep substantia propria $(>0.1 \mathrm{~mm}$ from the epithelial basement membrane). With 17 specimens a deep count was not possible because of insufficient depth of biopsied tissue. In the majority of cases at least three or four sections per specimen had to be assessed to obtain an adequate area of conjunctiva for analysis. Therefore, sections were cut at a minimum of $20 \mu \mathrm{m}$ apart to provide a different population of cells in each section. The area of vessels within the substantia propria, organised lymphocytic follicles, or tissue artefacts within fields of assessment, was determined for each observed field using the square grating eyepiece graticule. An equivalent area of extravascular tissue was then assessed over and above the original area such that each cell count represented the number of cells in $0.2 \mathrm{~mm}^{2}$ of extravascular connective tissue. As a result, cells within vessels were not counted.

\section{GLAUCOMA FILTRATION SURGERY (BRITISH} PATIENTS)

Sixty three patients underwent a Cairns type trabeculectomy. ${ }^{20}$ Following insertion of a superior rectus suture, a fornix or limbus based conjunctival flap was raised and the sclera exposed at the 12 o'clock position. Bipolar diathermy was used to establish haemostasis. A rectangular scleral flap measuring approximately $4 \times 3 \mathrm{~mm}$ and of approximately half scleral thickness, was raised adjacent to the limbus and this was followed by resection of a block of limbal tissue measuring approximately $3 \times 1 \mathrm{~mm}$. The block included the trabecular zone but excluded the scleral spur. A peripheral iridectomy was then performed and the scleral flap reapposed with between two and four 10/0 nylon sutures. The conjunctiva was closed with interrupted $10 / 0$ nylon sutures and subconjunctival injections of an antibiotic (cefuroxime $125 \mathrm{mg}$; 
Zinacef, Glaxo, Uxbridge) and a steroid (betamethasone $4 \mathrm{mg}$; Betnesol, Glaxo, Uxbridge) were administered. In a further five patients a Cairns type trabeculectomy was performed in conjunction with extracapsular cataract extraction and intraocular lens implantation (triple procedure). In these cases the trabeculectomy was conducted in the same manner, except that a routine extracapsular cataract extraction with

Figure 1. Mean conjunctival cell counts for (A) the epithelium, $(B)$ superficial substantia propria, and $(C)$ deep substantia propria, comparing counts from black and white patients who underwent primary trabeculectomy.
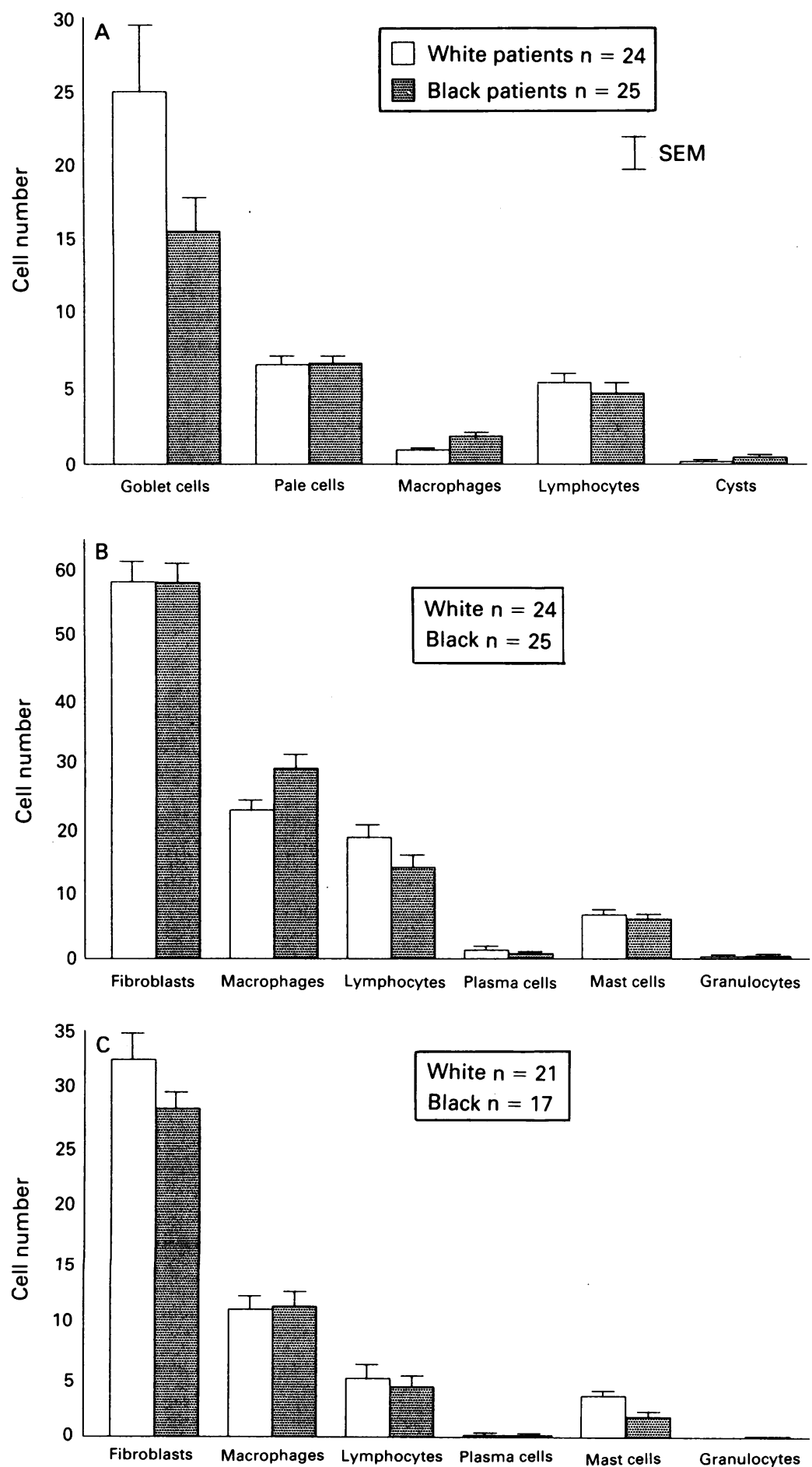

Cell type
Maxidex, Alcon, Watford) at least four times a day for a minimum of 6 weeks. The procedures were performed by a number of different surgeons but all on patients under the care of one consultant (RH).

Surgical success was defined as an IOP $<22$ $\mathrm{mm} \mathrm{Hg}$, without medication with failure defined as an IOP $>21 \mathrm{~mm} \mathrm{Hg}$, with or without medication. Partial success was defined as an IOP $<22$ $\mathrm{mm} \mathrm{Hg}$, with or without additional medication. Surgical outcome was only assessed after cessation of postoperative steroid therapy. Optic disc, visual field, and visual acuity criteria for success were not analysed, so that the outcome of filtration surgery was assessed on the single criterion of IOP control.

The patients were followed closely in a glaucoma clinic. The patients were seen on the first postoperative day, at 1 week and, unless there were complications or signs of potential failure, at 1 month, 3 months and every 3 or 4 months subsequently. When clinically indicated patients were seen more frequently. Data available from the most recent clinic visit was used in the final determination of surgical outcome to maximise the duration of follow up. If failure occurred, the exact time to failure was recorded to the nearest postoperative month. Rather than looking at success rates at one time point (the end of follow up), it was thus possible to determine success taking the length of follow up into account. The minimum follow up period was 6 months.

\section{STATISTICAL ANALYSIS}

Non-parametric statistics (Mann-Whitney U test) were used to compare cell counts between the patient groups. A $\chi^{2}$ test was used to compare binary patient data (such as race, sex, eye, or previous laser therapy) between the patient groups. These tests were performed using the CStat statistical package (Oxtech Ltd, Oxford). Graphical representation of trabeculectomy outcome was made using Kaplan-Meier survival analysis with the aid of SERC's EGRET package (Statistics and Epidemiology Research Corporation, Seattle, USA). Survival curves were plotted for the two groups of patients. Statistical evaluations of the differences in surgical success between the groups were determined by a log rank test (Mantel-Haenszel). There was an insufficient number of patients who had undergone a triple procedure to allow statistical analysis of this subgroup.

To analyse the effect of different conjunctival cell counts on the outcome of surgery the patients who had undergone trabeculectomy were divided into successes and failures. Comparisons between the cell counts of the two groups were made for each cell type using a nonparametric Mann-Whitney U test.

\section{Results}

STUDY A: A COMPARISON BETWEEN THE CONJUNCTIVAL CELL PROFILE OF BLACK AND WHITE PRIMARY TRABECULECTOMY PATIENTS The white patients had been exposed to a 
Figure 2. Mean conjunctival cell counts for (A) the epithelium, $(B)$ superficial substantia propria, and $(C)$ deep substantia propria comparing counts from black and white patients matched on non-racial risk factors for failure of filtration surgery.
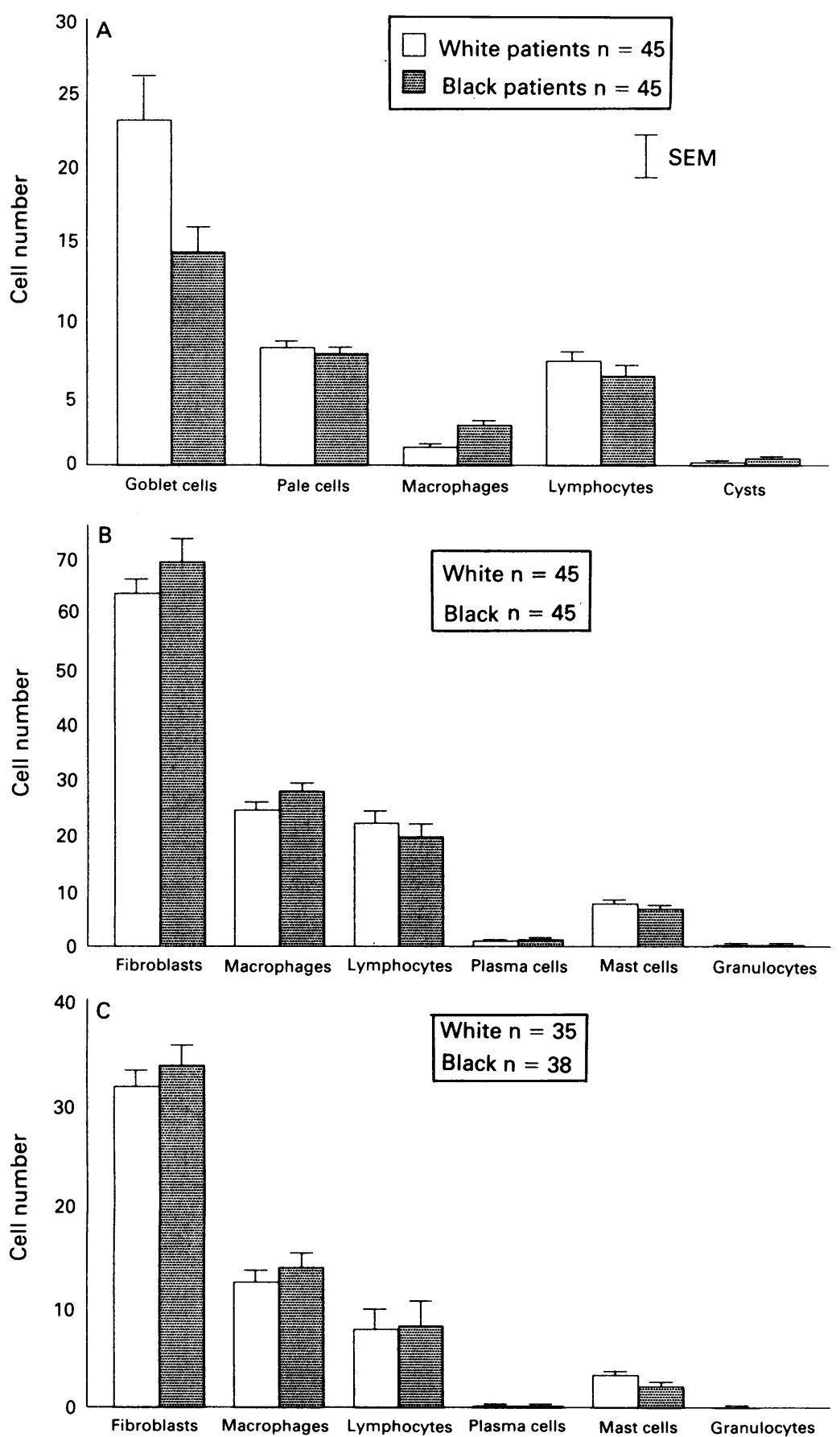

Cell type epithelium $(p=0.01)$ and superficial substantia propria $(\mathrm{p}<0.01)$ and fewer mast cells $(\mathrm{p}<0.01)$ in the deep substantia propria (see Fig 1). There was a tendency for black patient conjunctiva to contain fewer goblet cells but due to high variability in goblet cell counts in both racial groups the difference was not significant. No

difference between African and Afro-Caribbean conjunctiva was identified. tion than the black patients $(\mathrm{p}<0 \cdot 001)$. However, the groups were considered comparable, since no patient had received more than 6 weeks of medication and this was thought to be negligible in terms of the effect that such therapy could exert on the conjunctiva. The two groups did not differ statistically with respect to other factors (see Table 1).

The conjunctiva of black patients was found to contain significantly more macrophages in the

\section{STUDY B: A COMPARISON BETWEEN THE}

CONJUNCTIVAL CELL PROFILE OF BLACK AND WHITE PATIENTS MATCHED FOR NON-RACIAL RISK FACTORS

The conjunctiva of black patients was found to contain significantly more macrophages in the epithelium $(p<0.05)$ and also fewer goblet cells $(\mathrm{p}<0.01)$ (see Fig 2). There was a tendency for the conjunctiva of black patients to contain more macrophages in the superficial substantia propria, but this was not significant $(p=0 \cdot 07)$. In addition, there was a tendency for the conjunctiva of black patients to contain more fibroblasts in both superficial and deep substantia propria, but these differences were not significant.

Exclusion of minority cases (patients with PACG, PDS, PXF, uveitic, or traumatic glaucoma or those who had undergone previous surgery or laser therapy) made no difference to the significantly different cell counts.

By simple light microscopic examination, the conjunctival biopsies obtained from patients with PDS or PXF showed no differences in comparison with those obtained from patients with POAG. Specific stains for PXF material were not employed.

STUDY C: THE RESULTS OF GLAUCOMA FILTRATION SURGERY

Follow up was available for 45 white and 23 black patients who had undergone filtration surgery. The results of these procedures are summarised in Table 3.

\section{Initial trabeculectomy}

Follow up was available for 40 white and 15 black patients (all British) who had undergone their first trabeculectomy. Data for these patients are shown in Table 4.

The white patients were significantly older than the black patients $(\mathrm{p}<0 \cdot 05)$ by a mean difference of 10 years. There was a male predominance in the white group and the white patients tended to have received a shorter duration of preoperative therapy with topical medications, although the difference was not significant.

The success rate for trabeculectomy in white patients $(80 \%)$ was greater than that for black patients $(67 \%)$. Kaplan-Meier survival curves for this data are shown in Figure 3. However, the difference in trabeculectomy success between

Table 3 The outcome of filtration surgery in black and white patients

\begin{tabular}{|c|c|c|c|c|}
\hline \multirow[b]{2}{*}{ Procedure } & \multicolumn{2}{|c|}{ White patients } & \multicolumn{2}{|c|}{ Black patients } \\
\hline & $n$ & $\begin{array}{l}\text { Success } \\
(\%)\end{array}$ & $n$ & $\begin{array}{l}\text { Success } \\
(\%)\end{array}$ \\
\hline $\begin{array}{l}\text { 1st Trabeculectomy } \\
\text { 2nd Trabeculectomy } \\
\text { Triple procedure } \\
\text { lst Trabeculectomy in aphakic }\end{array}$ & $\begin{array}{r}40 \\
3 \\
1\end{array}$ & $\begin{array}{r}80 \\
33 \\
100\end{array}$ & $\begin{array}{r}15 \\
4 \\
4\end{array}$ & $\begin{array}{l}67 \\
25 \\
50\end{array}$ \\
\hline $\begin{array}{c}\text { eye } \\
\text { Total }\end{array}$ & $\begin{array}{r}1 \\
45\end{array}$ & $\begin{array}{r}0 \\
76\end{array}$ & $2 \overline{3}$ & $5 \overline{6}$ \\
\hline
\end{tabular}


Table 4 Data for black and white patients for whom follow up was available following their first trabeculectomy

\begin{tabular}{lll}
\hline & $\begin{array}{l}\text { White } \\
(n=40)\end{array}$ & $\begin{array}{l}\text { Black } \\
(n=15)\end{array}$ \\
\hline Mean age (SEM) [range] - years & $56(2 \cdot 0)$ & $46(4 \cdot 4)$ \\
Sex: & $23-76]$ & {$[25-85]$} \\
Male & 25 & 7 \\
Female & 15 & 8 \\
Eye: & 22 & 6 \\
Left & 18 & 9 \\
Right & 33 & 13 \\
Diagnosis: & 2 & - \\
POAG & 2 & - \\
PXF & -2 & 1 \\
PDS & 2 & 1 \\
PACG & 1 & - \\
Uveitic & 0 & 0 \\
Traumatic & 0 & 1 \\
Previous surgery & 2 & 2 \\
Previous laser therapy: & & \\
LI & $20 \cdot 1(6 \cdot 4)$ & $31 \cdot 7(21 \cdot 0)$ \\
LTP & $25 \cdot 6[6-84]$ & $15 \cdot 1[6-81]$ \\
Mean duration of topical therapy & 80 & 67 \\
(SEM)-months & 98 & 80 \\
Follow up (months) & Complete success (\%) &
\end{tabular}

POAG = Primary open angle glaucoma; $P X F=$ pseudoexfoliation syndrome; $\mathrm{PDS}=$ pigment dispersion syndrome; $\mathrm{PACG}=$ primary angle closure glaucoma; $\mathrm{LI}=$ laser iridotomy; $\mathrm{LTP}=$ laser trabeculectomy.

the two groups was not significant (MantelHaenszel log rank test $p=0 \cdot 1$ ). The relatively small number of black patients and the small number of failures in either group may be responsible for the failure of the difference to reach significance. In order to exclude patient selection bias, the analysis was repeated with matched pairs of black and white patients. Only 13 pairs of patients had undergone a first trabeculectomy for which there was adequate follow up. The results of this analysis were essentially the same as for the initial, larger analysis and the small number of patients and failures was probably responsible for the fact that the lower success rate for black patients did not reach statistical significance.

STUDY D: THE RELATION BETWEEN CONJUNCTIVAL CELL COUNTS AND THE OUTCOME OF

\section{TRABECULECTOMY}

For this analysis, data for the patients whose trabeculectomies were successful were compared with the data of the patients whose surgery failed (see Table 5).

The patients whose trabeculectomies failed were significantly younger $(p<0.05)$ and had received more topical medication before surgery $(\mathrm{p}<0.02)$ than those whose surgery was successful. No other differences between the two groups reached statistical significance, although with

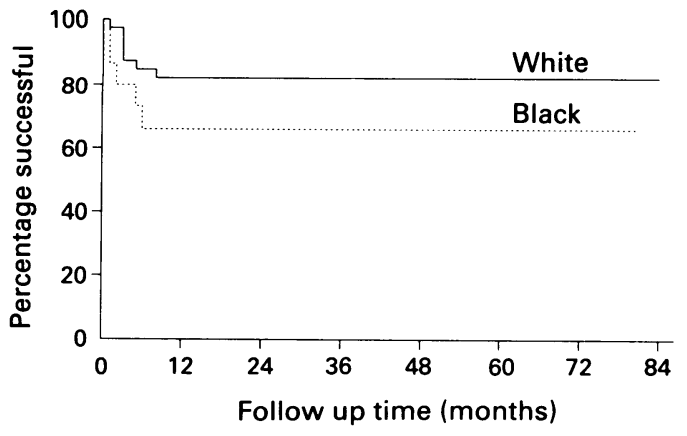

Table 5 Data for patients for whom follow up was available following their first trabeculectomy based on success of surgery

\begin{tabular}{lll}
\hline & $\begin{array}{c}\text { Success } \\
(n=42)\end{array}$ & $\begin{array}{l}\text { Failure } \\
(n=13)\end{array}$ \\
\hline Mean age (SEM) [range] - years & $\begin{array}{c}56(2 \cdot 2) \\
{[24-85]}\end{array}$ & $\begin{array}{c}45(4 \cdot 0) \\
{[23-59]}\end{array}$ \\
Sex: & 24 & 8 \\
$\quad$ Male & 18 & 5 \\
Female & 22 & 6 \\
Eye: & 20 & 7 \\
$\quad$ Left & & \\
Right & 36 & 10 \\
Diagnosis: & 2 & - \\
POAG & 2 & - \\
PXF & 1 & - \\
PDS & 1 & 2 \\
PACG & - & 1 \\
Uveitic & & \\
Traumatic & 0 & 0 \\
Previous laser therapy: & 1 & 3 \\
$\quad$ LI & & \\
LTP & $21 \cdot 8(8 \cdot 4)$ & $39 \cdot 8(11 \cdot 0)$ \\
Mean duration of topical therapy & SEM)-months &
\end{tabular}

POAG = Primary open angle glaucoma $\mathbf{P X F}=$ pseudoexfoliation $P O A G=$ Primary open angle glaucoma,$P X F=$ pseudoexfoliation
syndrome; $P D S=$ pigment dispersion syndrome; $P A C G=$ primary syndrome; $P D S=$ pigment dispersion syndrome; $P A C G=$
angle closure glaucoma; $L I=$ laser iridotomy; $L$ TP=laser trabeculoplasty.

respect to glaucoma diagnosis or previous laser therapy the numbers were too small for meaningful analysis.

Conjunctiva from patients whose trabeculectomies failed was found to contain significantly more pale cells $(p=0.01)$ and macrophages $(p=$ 0.01 ) in the epithelium, and more fibroblasts $(p=0.05)$ and macrophages $(p<0.05)$ in superficial substantia propria (see Fig 4).

\section{Discussion}

In many respects, primary open angle glaucoma in black patients is different from the condition in white patients. The disease appears to be more prevalent, to have onset at a younger age, to be more resistant to medical and laser therapy, and to be more aggressive, resulting in blindness more frequently and at a younger age than in white patients. ${ }^{2}$

Assessments of filtration surgery in black patients have shown variable rates of success (see Table 6)..$^{13-1522-36}$ Although surgical success in black patients has been reported to be greater by some groups, ${ }^{32+36}$ than others, ${ }^{131+24}$ it is generally accepted that the success of glaucoma filtration surgery in black patients is not as high as with white patients. Comparisons made between studies can be misleading for various reasons such as varying criteria for success, diagnostic categories, follow up periods, and operating facilities or techniques. The latter factors are of particular relevance when comparing the studies on black patients, both with each other and also with studies on white patients. The American black population differs from the African in many respects including health education and patient understanding. A major problem with studies in Africa, for example, has been the high proportion of patients lost to follow up (see Table 6). When large numbers of patients are lost to follow up it is impossible to know whether the majority of defaulters are successes or failures. Study design failings, such as nonrandomisation, lack of controls, inadequate numbers of patients, or insufficient statistical 
Figure 4 Mean conjunctival cell counts for (A) the epithelium, $(B)$ superficial substantia propria, and $(C)$ deep substantia propria, comparing counts from the patients whose trabeculectomy was successful with those whose failed.
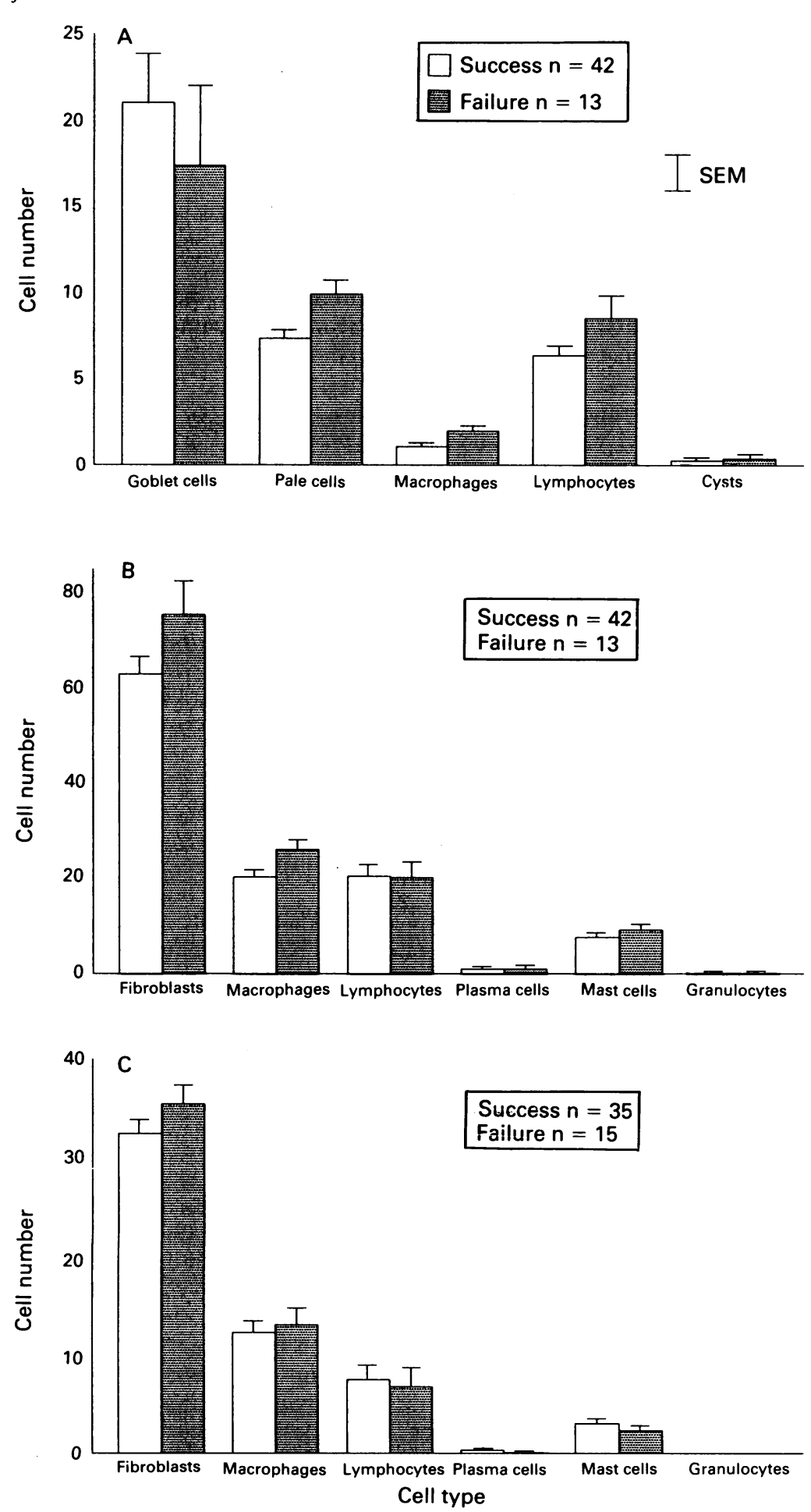

Cell type

analysis have added to the problem of comparing the results of filtration surgery between studies. Little attention has been paid to the effect of the high prevalence of onchocerciasis in parts of Africa. A relation between the prevalence of onchocerciasis and glaucoma may exist, without it causing obvious secondary glaucoma. ${ }^{31}$ Since patients with onchocerciasis tend to fare less well after filtering surgery, ${ }^{2631}$ studies performed in the parts of Africa where onchocerciasis is prevalent may show lower success rates because of concurrent disease rather than true racial factors. Age may also be an important factor when considering studies of black patients. Black patients undergoing trabeculectomy may well be younger on average than white patients, since
POAG tends to present earlier in black patients this was the finding in our study. Since young age is a risk factor for failure, studies on black patients may report lower success rates than can be attributed to race alone. Our results showed that in addition to a lower surgical success rate, the black patients in study $\mathrm{C}$ were significantly younger than the white patients. Furthermore, the results of study D showed that the patients whose trabeculectomies failed were significantly younger. Thus age-related factors (conjunctival or other) may be of more importance than specific racial differences in explaining higher rates of filtration failure in black patients.

Another factor of importance is the amount of previous topical therapy. Patients in different studies have been exposed to different amounts and/or types of topical medication. In most studies negligible information about previous medication has been provided. The growing evidence for an adverse effect of topical medication on the outcome of filtration surgery ${ }^{9-12}$ indicates that failure to take this into account is a further source of error. The results of study $\mathrm{C}$ showed that the black patients had a tendency to have received topical medications for a longer duration. Furthermore, study D showed that the patients whose trabeculectomies had failed had received significantly more topical medication than those whose surgery was successful. Thus, the adverse effect of topical medication may play a significant role over and above racial differences. It is of interest and potential importance that, in previously reported studies, the better results of trabeculectomy in black patients were the outcome of primary procedures, ${ }^{323+36}$ rather than trabeculectomy performed after failure of medical therapy. Medical therapy in Africa is frequently unsatisfactory for financial, educational, and logistic reasons. Irregular supplies of drugs and inconstant application make medical management of glaucoma inadequate. It is not surprising, therefore, that primary trabeculectomy is frequently performed in developing countries. If primary trabeculectomy is more frequently successful in black patients, it may, at least partially, explain the tendency to higher success rates for African blacks in comparison with American blacks who are usually only treated surgically after failure of maximum medical therapy (see Table 6). A particularly adverse effect of topical medications on the conjunctiva of black patients may be important in this respect but remains unsubstantiated.

A large well designed prospective study would be useful to determine the degree of racial difference in the results of trabeculectomy. Despite the variation in the reported success rates for filtration surgery in black patients the clinical impression remains that these patients have a greater tendency to surgical failure than white patients.

A number of reasons have been proposed to explain why filtration failure appears to be more common in black patients. $\mathrm{McNair}^{37}$ proposed a thicker Tenon's capsule in black patients as a risk factor for failure of filtration surgery and some workers thus advocated partial tenectomy at the time of filtration surgery. ${ }^{2638} \mathrm{Welsh}^{39}$ considered Tenon's capsule to be of normal 
Table 6 Summary of the results of filtration surgery in black patients showing year, country, patient numbers, type of procedure, criteria for success, duration of follow up, number of patients lost to follow up, complete success rate, and partial success rate

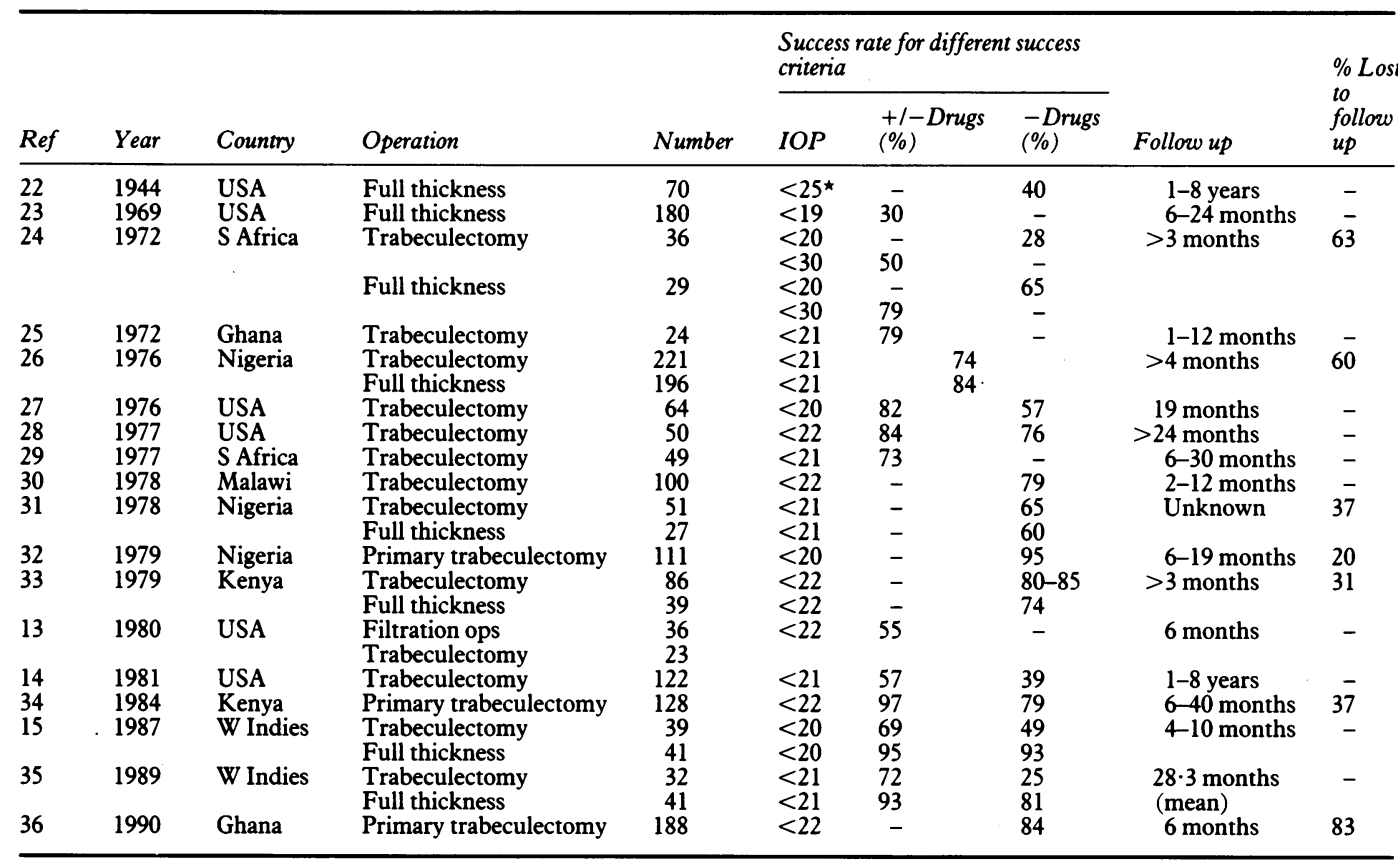

^With maintenance of visual acuity and field.

thickness in black patients, but that it was capable of a greater reaction following surgical trauma than in white patients. Thus, in a later report, he advocated tenectomy at the time of filtration surgery. ${ }^{24}$ However, no comparative, prospective, case-controlled studies investigating excision of Tenon's capsule in black patients have been published and there are few reports on this subject in white patients. Gorin ${ }^{40}$ considered it best to avoid any manipulation of Tenon's capsule, Maumenee ${ }^{41}$ reported that excision of subconjunctival tissue did not improve success, whereas Stewart $e t a l^{42}$ reported that tenectomy was advantageous. In the only comparative study of trabeculectomy with and without tenectomy, Kapetansky ${ }^{43}$ reported no statistically significant difference between the two groups. The control of IOP in black patients undergoing trabeculectomy with tenectomy $(n=6)$ or without tenectomy $(n=8)$ were not significantly different from those of the white patients. Unfortunately the requirement for additional medical therapy was not addressed and there may have been a difference between the two groups in terms of partial success. The advantages or disadvantages of tenectomy at the time of trabeculectomy, thus remain unknown. A large prospective study is required to determine if and when tenectomy is indicated.

The main reason proposed to explain why failure of trabeculectomy in black patients may be more likely than in white patients is that black patients have a more aggressive wound healing response. Since there is not doubt that there is an increased risk of keloid skin scars in black patients, ${ }^{44}$ it seems reasonable to expect exaggerated wound healing of ocular tissues. A study of eyes enucleated after failure of filtering surgery has shown more episcleral scarring in eyes from black patients compared with those from white patients ${ }^{45}$ and excessive wound healing in response to surgical trauma was identified by Welsh ${ }^{39}$ as the cause of the increased risk of failure. Luntz and $\mathrm{Smith}^{46}$ found pathological episcleral fibrosis in black patients undergoing filtration surgery and proposed that a difference in the preoperative state of the episclera of black patients was a risk factor for filtration failure. However, the latter proposal was based on the observations of only four patients and Welsh ${ }^{39}$ found no clinical abnormality of the episclera in most of the 143 eyes in his study.

Differences between black and white skin have been documented previously. Although there are few major structural or functional dissimilarities between black and white skin, ${ }^{47}$ disease processes do differ ${ }^{44}$ 48-50 $^{-1}$ and minor variations exist which partially reflect that black skin is better able to withstand solar irradiation. ${ }^{51}{ }^{52}$ In the only study which has assessed differences in the cellular profile of black and white skin, Montagna and Carlisle ${ }^{52}$ reported that black skin contained more fibroblasts, macrophages, and multinucleated giant cells.

Only one previous study has determined cellular differences between the conjunctiva of patients of different races. ${ }^{53}$ In this study conjunctiva from 11 white patients was found to contain more mast cells and neutrophils than that from 20 black American patients. The authors thus felt that the racial variation in the number of conjunctival cells was not related to differences in the outcome of filtration surgery. The results of this study were at variance with our findings, except for the demonstration that the conjunctiva of white patients contained more mast cells.

The main finding of our study was that conjunctiva from black patients was found to contain more macrophages. Also of importance was the finding that the conjunctiva of black patients tended to contain more fibroblasts. Furthermore, it was shown that conjunctiva from patients whose subsequent filtration 
surgery failed also contained more macrophages and fibroblasts. Fibroblasts are the key cells of wound healing but macrophages also play a major role in wound healing and our findings are thus of potential significance in explaining the exaggerated wound healing response in black patients.

Macrophages remove damaged and exogenous material in the early phase of wound healing and are crucial for tissue remodelling in the later phases. ${ }^{545}$ Phagocytosis, however, is not their only role, for they also release enzymes which augment tissue degradation; generate chemotactic factors which recruit inflammatory cells; interact with lymphocytes and are important in antigen presentation; produce cytokines; and cause accumulation and proliferation of fibroblasts and endothelial cells, with subsequent fibrosis and angiogenesis. ${ }^{56-58}$ Macrophages are thought to be a principal source of fibrogenic and angiogenic cytokines such as macrophage and platelet derived growth factors, tumour necrosis factor, and transforming growth factors $\alpha$ and $\beta,{ }^{5699-64}$ so that activation of such cells is critical for normal wound healing and amplified macrophage activity may result in excessive wound healing. Conjunctiva from patients whose subsequent surgery failed contained more macrophages, providing evidence that the increased number of macrophages identified in the conjunctiva of black patients may predispose such individuals to a greater risk of filtration failure.

Our study of 'primary trabeculectomy' conjunctiva (study A) showed that conjunctiva from white patients contained more mast cells than that from black patients. McMillan $e t a l^{53}$ found the same difference in their study. Mast cells play a major role in type I hypersensitivity, but are also involved in the acute inflammatory response, the control of local blood flow, and angiogenesis. ${ }^{65-67}$ The reason why the conjunctiva of white patients contains more mast cells and the importance of this with respect to wound healing remains unknown.

Our study of 'matched patient' conjunctiva (study B) showed that conjunctiva from black patients contained fewer goblet cells than that from white patients. It is unlikely that a reduced number of goblet cells can explain an increased wound healing response, but it is of interest to speculate why this difference existed. Goblet cell numbers have been shown to be reduced after long term exposure to topical medications. ${ }^{68} \mathrm{It}$ is interesting, therefore, that a difference in goblet cell number was not found in our comparison between 'primary trabeculectomy' conjunctiva but was found when including patients previously treated with topical drugs. The apparent inconsistency may imply a greater adverse effect of previous topical medication on goblet cell number in black compared with white patients.

Our study also found that, in addition to macrophages, conjunctiva from patients whose subsequent surgery failed contained more fibroblasts and pale cells (study D). Since fibroblasts are the collagen producing cells of wound healing it is understandable that patients whose conjunctiva contain more fibroblasts may have a greater healing response. The greater number of pale cells is more difficult to interpret.
These include antigen presenting Langerhans cells and it may be that these cells enhance wound healing in some manner. The results of this part of the study are complicated by the fact that the patients whose trabeculectomies failed were younger and had been treated with more topical therapy in addition, more frequently, to being black. Thus it is not possible to know to which factor(s) the conjunctival differences related. Determination of the true conjunctival cellular differences between successful and unsuccessful patients would require a balance of other risk factors in the two groups in order to abolish additional effects on the conjunctiva from these risk factors themselves.

Cell number may not be the only important racial difference and there may be variations in cell activation and function which are equally relevant. Differences between black and white patient fibroblasts have been reported ${ }^{69-71}$ but as yet racial variability with other cells has not been reported. Quantitative or qualitative differences in cytokine production under genetic control may be of particular relevance and could be far more important than quantitative differences in cell populations. Other potential racial factors, which may play a part in determining specific wound healing characteristics of black or white patients, include different degrees of vascular reactivity (postoperative hyperaemia) $)^{72}$ or aqueous humour composition. ${ }^{73}$

The ideal management of black patients undergoing trabeculectomy remains unknown. Our results have shown that racial cellular differences do exist and that these can be related to differences in the wound healing response. The results support the concept that black patients are at increased risk of filtration failure owing to an exaggerated wound healing response and a different cellular profile of the conjunctiva may be, at least partially, responsible for this. On this basis the use of antimetabolites such as 5-fluorouracil or mitomycin C may be indicated in all black patients undergoing filtration surgery. Preoperative treatment with steroids (topical or systemic) or other anti-inflammatory agents may be of particular help in these patients. Future pharmacological development may provide specific antimacrophage drugs which, on the basis of this study, would be of potential value in black patients. Furthermore, since there is evidence for higher success rates following primary surgery, earlier surgical intervention may prove to be ideal for these high risk patients.

The authors are grateful to Dr R Barbe of the Eye Hospital, Lunsar, Sierra Leone and to both Mr A Foster and Miss C Gilbert of the Department of Preventive Ophthalmology, Institute of Ophthalmology, London, for supplying the African patient conjunctival biopsies.

David Broadway is supported by the T F C Frost Trust, London.

1 Migdal CS, Hitchings RA. The role of early surgery for openangle glaucoma. Ophthalmol Clin N Am 1991; 4: 853-9.

2 Gressel MG, Heuer DK, Parrish RK. Trabeculectomy in young patients. Ophthalmology 1984; 91: 1242-6.

3 Herschler J. Medically uncontrolled glaucoma in the aphakic eye. Ann Ophthalmol 1981; 13: 909.

4 Inaba Z. Long-term results of trabeculectomy in the Japanese: an analysis by life-table method. $\mathcal{F} p n \mathcal{F}$ Ophthalmol 1982; 26: an analysis

5 Heuer DK, Gressel MG, Parrish RK, Anderson DR, Hodapp E, Palmberg PF. Trabeculectomy in aphakic eyes. Ophthalmology 1984; 91 : 1045-51.

mology $1984 ; 91$ : $1045-51$.
6 Mills KB. Trabeculectomy: a retrospective long-term followup of 444 cases. Brf Ophthalmol 1981; 65: 790-5. 
7 Allen RC, Bellows AR, Hutchinson BT, Murphy SD. Filtration surgery in the treatment of neovascular glaucoma. Ophthalmology 1982;89: 1181-7.

8 Katz LJ, Spaeth GL. Surgical management of the secondary glaucomas: Part I. Ophthalmic Surg 1987; 18: 826-34.

9 Lavin MJ, Wormald RPL, Migdal CS, Hitchings RA. The influence of prior therapy on the success of trabeculectomy Arch Ophthalmol 1990; 108: 1543-8.

10 Longstaff S, Wormald RPL, Mazover A, Hitchings RA Glaucoma triple procedures: efficacy of intraocular pressure control and visual outcome. Ophthalmic Surg 1990; 21 786-93

11 Miller MH, Rice NSC. Trabeculectomy combined with $\beta$ irradiation for congenital glaucoma. Br $\mathcal{F}$ Ophthalmol 1991 75: $584-90$.

12 Broadway DC, Grierson I, Hitchings RA. Adverse effects of topical anti-glaucomatous medications on the conjunctiva. Br f Ophthalmol 1993; 77: 790-6.

13 Merritt JC. Filtering procedures in American blacks. Ophthalmic Surg 1980; 11: 91-4.

14 Miller RD, Barber JC. Trabeculectomy in black patients. Ophthalmic Surg 1981; 12: 46-50.

15 Shingleton BJ, Distler JA, Baker BH. Filtration surgery in black patients: early results in a West Indian population. Ophthalmic Surg 1987; 18: 195-9.

16 Skuta GL, Parrish II RK. Wound healing in glaucoma filtering surgery. Surv Ophthalmol 1987; 32: 149-70.

17 Hitchings RA, Grierson I. Clinico pathological correlation in eyes with failed fistulizing surgery. Trans Ophthalmol Soc UK 1983; 103: 84-8.

18 Birbeck MS, Breathnach AS, Everall JD. An electron microscope study of basal melanocytes and high-level clear cells (Langerhans cells) in vitiligo. $\mathcal{F}$ Invest Dermatol 1961; 37: $51-64$.

19 Abdel-Khalek LMR, Williamson J, Lee WR. Morphological changes in the human conjunctival epithelium. I. In the changes in the human conjunctival epithelium. I. In the

20 Cairns JE. Trabeculectomy: preliminary report of a new Cairns JE. Trabeculectomy: preliminary r
method. Am $\mathcal{F}$ Ophthalmol 1968; 66: 673-9.

21 Cowan CL, Worthen DM, Mason RP, Anduze AL. Glaucoma in blacks. Arch Ophthalmol 1988; 106: 738-9.

22 Iliff CE. Surgical control of glaucoma in the negro. Am $f$ Ophthalmol 1944; 27: 731-8.

23 Berson D, Zauberman H, Landau L, Blumenthal M. Filtering operations in blacks. Am f Ophthalmol 1969; 67: 395-8.

24 Welsh NH. Trabeculectomy with fistula formation in the African. Brf Ophthalmol 1972; 56: 32-6.

25 Chatterjee S, Ansari MW. Microsurgical trabeculectomy in Ghana. Brf Ophthalmol 1972; 56: 783-7.

26 Kietzman B. Glaucoma surgery in Nigerian eyes: a five-year study. Ophthalmic Surg 1976; 7: 52-8.

27 Freedman J, Shen E, Ahrens M. Trabeculectomy in a black American glaucoma population. Br F Ophthalmol 1976; 60: $573-4$

28 Ferguson JG, Macdonald R. Trabeculectomy in blacks: a twoyear follow-up. Ophthalmic Surg 1977; 8: 41-3.

29 David R, Freedman J, Luntz MH. Comparative study of Watson's and Cairns's trabeculectomies in a black population with open angle glaucoma. Br $\mathcal{F}$ Ophthalmol 1977; 61 . $117-9$

30 BenEzra D, Chirambo MC. Trabeculectomy. Ann Ophthalmo 1978; 10: 1101-5.

31 Sandford-Smith JH. The surgical treatment of open-angle glaucoma in Nigerians. Brf Ophthalmol 1978; 62: 283-6.

32 Thommy CP, Bhar IS. Trabeculectomy in Nigerian patients with open-angle glaucoma. $\mathrm{Br} \mathcal{F}$ Ophthalmol 1979; 63: 636-42.

33 Bakker NJA, Manku SI. Trabeculectomy versus Scheie's operation: a comparative retrospective study in openoperation: a comparative retrospective study in openangle glau-5.

34 Adala HS, Klauss V. Causes of failure of trabeculectomy (TET) among Kenyan Africans. East Afr Med F 1984; 61 : 246-53.

35 Wilson MR. Posterior lip sclerectomy vs trabeculectomy in West Indian blacks. Arch Ophthalmol 1989; 107: 1604-8.

36 Verrey JD, Foster A, Wormald R, Akuamoa C. Chroni glaucoma in Northern Ghana - a retrospective study of 397 patients. Eye 1990; 4: 115-20 37 McNair SS. Chronic simple glaucoma in the negro. Am $\mathcal{F}$

38 Ben Sira I, Ticho U. Excision of Tenon's capsule in fistulizing operations on Africans. Am f Ophthalmol 1969; 68: 336-40.

39 Welsh NH. Failure of filtration operations in the African. $B r f$ Ophthalmol 1970; 54: 594-8.

40 Gorin G. Use of a thin conjunctival flap in limbosclerectomy. Ann Ophthalmol 1971; 3: 258-63.

41 Maumenee AE. Mechanism of filtration of fistulizing glaucoma procedures. In: Symposium on glaucoma; Transactions of the New Orleans Acadamy of Ophthalmology. St Louis Mosby, 1981: 280-8.
42 Stewart RH, Kimborough RL, Bachh H, Allbright M. Trabeculectomy and modifications of trabeculectomy. Ophthalmic Surg 1979; 10: 76-80.

43 Kapetansky EM. Trabeculectomy, or trabeculectomy plus enectomy: a comparative study. Glaucoma $1980 ; 2: 451-3$.

44 Kelly AP. Keloids. Dermatol Clin 1988; 6: 413-24.

45 Friedenwald JS. Some problems in the diagnosis and treat ment of glaucoma. Am F Ophthalmol 1950; 33: 1523-38.

46 Luntz MH, Smith R. A possible aetiology for glaucoma in negroes. Brf Ophthalmol 1960; 44: 600-5.

47 McDonald CJ. Structure and function of the skin: are there differences between black and white skin? Dermatol Clin 1988; 6: 343-7.

48 McLaurin CI. Cutaneous reaction patterns in blacks. Dermato Clin 1988; 6: 353-62.

49 Berardesca E, Maibach HI. Contact dermatitis in blacks Dermatol Clin 1988; 6: 363-8.

50 Andersen KE, Maibach HI. Black and white human skin differences. F Am Acad Dermatol 1979; 1: 276-82.

51 Berardesca E, de Rigal J, Leveque JL, Maibach HI. In vivo biophysical characterization of skin physiological differences in races. Dermatologica 1991; 182: 89-93.

52 Montagna W, Carlisle K. The architecture of black and white facial skin. F Am Acad Dermatol 1991; 24: 929-37.

53 McMillan TA, Stewart WC, Hennis HL, Hunt HH, Apple DJ. Histologic differences in the conjunctiva of black and white glaucoma patients. Ophthalmic Surg 1992; 23: 762-5.

54 Leibovich SJ, Ross R. The role of the macrophage in wound repair: a study with hydrocortisone and antimacrophage serum. Am $\mathcal{F}$ Pathol 1975; 78: 71-91.

55 Bryant SM, Fukasawa M, Orita H, Rodgers KE, diZerega GS Mediation of post-surgical wound healing by macrophages. Prog Clin Biol Res 1988; 266: 273-90.

56 Wong $\mathrm{H}$, Wahl S. Inflammation and repair. In: Sporn $M$ Roberts A, eds. Handbook of experimental pharmacology, Vol 95/II. Peptide growth factors and their receptors II. Berlin: 95/II. Peptide growth factors and
Springer-Verlag, 1990: 509-48.

57 Johnston RB. Immunology: monocytes and macrophages. N Engl F Med 1988; 318: 747-52.

58 Leibovich SJ, Wiseman DM. Macrophages, wound repair and angiogenesis. Prog Clin Biol Res 1988; 266: 131-45.

59 Kovacs EJ, Kelley J. Lymphokine regulation of macrophagederived growth factor secretion following pulmonary injury. Am $\mathcal{F}$ Pathol 1985; 121: 261-8.

60 Madtes DK, Raines EW, Sakariassen KS, Assoian KS, Sporn $\mathrm{MB}$, Bell GI, et al. Induction of transforming growth factor- $\alpha$ in activated human alveolar macrophages. Cell 1988; 53: 285-93.

61 Rapolee DA, Mark D, Banda MJ, Werb Z. Wound macrophages express TGF- $\alpha$ and other growth factors in vivo: analysis by mRNA phenotyping. Science 1988; 241: 708-12.

62 Pierce GF, Mustoe TA, Lingelbach J, Masakowski VR Gramates P, Deuel TF. Transforming growth factor- $\beta$ reverses the glucocorticoid-induced wound-healing deficit in rats: possible regulation in macrophages by platelet-derived growth

63 Piguet PF, Collart MA, Grau GE, Kapanci Y, Vassalli P. Tumor necrosis factor/cachectin plays a key role in bleomycin-induced pneumopathy and fibrosis. $\mathcal{F} \operatorname{Exp} M e d$ 1989; 170: 655-63.

64 Piguet PF, Collart MA, Grau GE, Sappino A-P, Vassalli P. Requirement of tumour necrosis factor for development of silica-induced pulmonary fibrosis. Nature 1990; 344: 245-7.

65 Irani A-MA, Schwartz LB. Mast cell heterogeneity. Clinical and Experimental Allergy 1989; 19: 143-55.

66 Wasserman SI. Mast cell biology. F Allergy Clin Immunol 1990; 86: $590-3$

67 Azizkhan RG, Azizkhan JC, Zetter BR, Folkman J. Mast cell heparin stimulates migration of capillary endothelial cells in vitro. 7 Exp Med 1980; 152: 931-44.

68 Sherwood MB, Grierson I, Millar L, Hitchings RA. Longterm morphologic effects of antiglaucoma drugs on the conjunctiva and Tenon's capsule in glaucomatous patients. Ophthalmology 1989; 96: 327-35.

69 Hatori N, Gardner JP, Tomonari H, Fine BP, Aviv A. Na ${ }^{+}$ $\mathrm{H}^{+}$antiport activity in skin fibroblasts from blacks and whites. Hypertension 1990; 15: 140-5.

70 Nakamura A, Gardner J, Hatori N, Nakamura M, Fine BP, Aviv A. Differences of $\mathrm{Ca}^{2+}$ regulation in skin fibroblasts from blacks and whites. $\mathcal{f}$ Cell Physiol 1989; 138: 367-74.

71 Kuriyama S, Hopp L, Tamura H, Lasker N, Aviv A. A higher cellular sodium turnover rate in cultured skin fibroblasts from blacks. Hypertension 1988; 11: 301-7.

72 Berardesca E, Maibach HI. Cutaneous reactive hyperaemia: racial differences induced by corticoid application. $\mathrm{Br} \mathcal{F}$ Dermatol 1989 ; 120: 787-94.

73 Herschler J, Litin BS. Biochemical abnormalities in the aqueous in chronic open-angle glaucoma. Ophthalmic Surg 1987; 18: 792-5. 